\title{
Taste and Smell Disturbances in Patients with Gastroparesis and Gastroesophageal Reflux Disease
}

\author{
Alisha Kabadi, Mohammed Saadi, Ron Schey, and Henry P Parkman* \\ Gastroenterology Section, Department of Medicine, Temple University School of Medicine, Philadelphia, PA, USA
}

\begin{abstract}
Background/Aims
Patients with gastroparesis and gastroesophageal reflux disease (GERD) often report decreased enjoyment when eating. Some patients remark that food does not smell or taste the same. To determine if taste and/or smell disturbances are present in patients with gastroparesis and/or GERD and relate these to gastrointestinal symptom severity.
\end{abstract}

\section{Methods}

Patients with gastroparesis and/or GERD completed questionnaires evaluating taste and smell (Taste and Smell Survey [TSS]), Patient Assessment of Upper Gastrointestinal Symptom Severity Index (PAGI-SYM), and Demographics. TSS questioned the nature of taste/ smell changes and the impact on quality of life. PAGI-SYM was used to calculate Gastroparesis Cardinal Symptom Index (GCSI) and Heartburn and Regurgitation Score (HB/RG).

\section{Results}

Seventy-six subjects were enrolled: healthy controls $(n=13)$, gastroparesis alone $(n=30)$, GERD alone $(n=10)$, and both gastroparesis and GERD $(n=23)$. Taste and smell disturbances were higher in patients with gastroparesis, GERD, and both gastroparesis and GERD compared to healthy controls. Taste and smell abnormalities were significantly correlated $(r=0.530, P<$ 0.001). Taste score was strongly correlated with $\mathrm{HB} / \mathrm{RG}(r=0.637, P<0.001)$ and with $\mathrm{GCSI}(r=0.536, P<0.001)$. Smell score was also strongly correlated to HB/RG $(r=0.513, P<0.001)$ and GCSI $(r=0.495, P<0.001)$.

\section{Conclusions}

Taste and smell abnormalities are prominent in gastroparesis and GERD patients. Abnormalities in taste and smell are significantly correlated with both gastroparesis and GERD symptom severity. Awareness of this high prevalence of taste and smell dysfunction among patients with gastroparesis and GERD may help to better understand the food intolerances these patients often have.

(J Neurogastroenterol Motil 2017;23:370-377)

\section{Key Words}

Gastroesophageal reflux; Gastroparesis; Smell; Taste

Received: August 17, 2016 Revised: November 2, 2016 Accepted: December 15, 2016

(a) This is an Open Access article distributed under the terms of the Creative Commons Attribution Non-Commercial License (http://creativecommons. org/licenses/by-nc/4.0) which permits unrestricted non-commercial use, distribution, and reproduction in any medium, provided the original work is properly cited.

*Correspondence: Henry P Parkman, MD Gastroenterology Section, Department of Medicine, Temple University School of Medicine, Parkinson Pavilion, 8th floor, 3401 North Broad Street, Philadelphia, PA 19140, USA Tel: +1-215-707-7579, Fax: +1-215-707-2684,E-mail: henry.parkman@temple.edu 
function are related to GI symptom severity.

\section{Introduction}

Gastroparesis is a chronic stomach motility disorder involving delayed emptying of solids and liquids in the absence of mechanical obstruction. Patients diagnosed with this disorder commonly experience nausea, vomiting, fullness, and abdominal discomfort. ${ }^{1,2}$ Gastroesophageal reflux disease (GERD), a common upper gastrointestinal disease, is characterized by persistent reflux of acidic gastric juices up into the esophagus due to a defect of the lower esophageal sphincter or excess acid production. GERD patients also suffer from numerous upper gastrointestinal (GI) symptoms including heartburn and regurgitation. ${ }^{3}$ Patients with both gastroparesis and GERD are advised to manage symptoms by eating less fats and decreasing the frequency and size of meals. ${ }^{4}$ From experience in practice, it has been observed that some patients with gastroparesis and with GERD attribute decreased enjoyment when eating to changes in taste and smell function. However, no prior studies have identified taste and smell abnormalities in these upper GI disorders.

Tastes are detected by gustatory receptors on the tongue, pharynx, epiglottis, and upper one-third of the esophagus that assess 4 main tastes: salt, sweet, sour, and bitter. Receptors responsible for olfactory function are located throughout the nasal respiratory epithelium. Both senses are innervated by multiple cranial nerves that send signals to the cortex for identification of odors and tastes and analysis of somatosensory overtones (irritation, burning, and potency). Destruction of these anatomical areas containing olfactory and gustatory receptors or degeneration of nerves innervating the receptors impacts sensitivity to smell and taste.

Abnormalities in taste and smell function are seen among the aging population. These sensory changes vary widely in severity and presentation and can be characterized as "the total absence of taste or smell, reduced or increased sensitivity, distortion of normal taste and smell, presence of phantom tastes or odors, and lingering bitter or metallic sensations." Such changes are also symptoms of many diseases and frequently impact the quality of life. Common causes of taste and smell alterations include long-term smoking, malignancy, head trauma, brain surgery, and neurodegenerative disorders. ${ }^{5}$

The aims of this study are to determine the prevalence of taste and/or smell disturbances in patients with gastroparesis and/or GERD. This particular patient population was selected to be studied based on the frequency of presentation of these disorders in the clinic. We also sought to analyze the nature of any changes in taste and/or smell and to determine if these changes in chemosensory

\section{Materials and Methods}

\section{Study Protocol}

Subjects with gastroparesis and/or GERD were asked to participate in the study after their clinic visit at the GI Motility Clinic at Temple University. Healthy controls were also recruited for the study. Individuals who agreed to participate were informed of the study purpose and protocol, and invited to ask any questions before signing the informed consent. The participants completed the Taste and Smell Survey (TSS), Patient Assessment of Upper Gastrointestinal Symptom Severity Index (PAGI-SYM), and a Demographics Questionnaire. An investigator was present throughout the process to answer any questions about the surveys.

\section{Patients}

The study population comprised of healthy controls and patients with gastroparesis and/or GERD seen in the GI Motility Clinic. Male and female subjects between the ages of 18 to 75 were eligible to participate in the study. Gastroparesis patients were selected based on delayed gastric emptying on gastric scintigraphy, and GERD patients were chosen based on a positive 24-hour esophageal $\mathrm{pH}$ test. Patients diagnosed with both gastroparesis and GERD were positive for both tests.

We excluded any subjects who received any prior surgery for treatment of gastroparesis or GERD. Subjects with any primary head or neck problems, prior head/brain or neck surgery or a history of brain or neck tumors were also excluded from the study.

Subjects completed 3 questionnaires as listed below. The study was approved by the Temple University Institutional Review Board and informed consent for each subject was obtained by one of the investigators.

\section{Questionnaires}

\section{Demographics questionnaire}

This questionnaire asked patients to report their age, gender, race, length of diagnosis with gastroparesis and/or GERD, and the type of gastroparesis. Participants listed any current medications, current medical problems, past medical conditions, and past surgeries. They were also asked about their alcohol usage and smoking history. 


\section{Patient Assessment of Upper Gastrointestinal Symptom Severity Index}

This validated questionnaire asks patients to rate the severity of 20 common gastrointestinal symptoms over the past 2 weeks: none (0), very mild (1), mild (2), moderate (3), severe (4), and very severe (5). Sixteen of the 20 items were used to calculate the Gastroparesis Cardinal Symptom Index (GCSI) and the Heartburn and Regurgitation Score (HB/RG). The GCSI was calculated based on the average score of 9 symptoms: nausea, retching, vomiting, stomach fullness, not able to finish a normal-sized meal, feeling excessively full after meals, loss of appetite, bloating, and a visibly larger stomach or belly. The $\mathrm{HB} / \mathrm{RG}$ was calculated based on the average score of 7 symptoms: heartburn during the day, heartburn when lying down, feeling of discomfort inside chest during day, feeling of discomfort inside chest at night, reflux/regurgitation during the day, reflux/regurgitation when lying down, and bitter/acid/sour taste in mouth.

\section{Taste and Smell Survey}

This is a 14-item validated questionnaire assessing taste and smell originally developed to evaluate chemosensory changes amongst $\mathrm{HIV}$-infected patients. ${ }^{7}$ The survey has since been widely used to assess taste and smell alterations in patients with lung cancer, head and neck cancer, and advanced cancer. ${ }^{6,8}$

Taste was evaluated by 9 items which asked patients to indicate any self-perceived changes in their sense of taste or tastes of particular foods, to assess whether they have noticed any changes (stronger or weaker) in the 4 main tastes (sweet, salty, bitter, and sour), and to rate the severity of changes. The 8 items were scored from $0-1$ points and 1 item was scored 1-2 points, resulting in an overall possible taste score from 1-10 points.

Smell was evaluated by 5 items. Items questioned patients if they have noticed changes in their sense of smell, whether particular foods or smell stronger or weaker, and how they would rate the severity of these changes. An overall smell score from 0-6 points was generated by scoring 4 of the items from $0-1$ points and 1 item from 0-2 points.

For all the questions, subjects were asked to compare their taste and smell senses at the time of data collection to before they were diagnosed with gastroparesis and/or GERD. Healthy controls were asked to compare their taste and smell senses to 10 years prior.

\section{Statistical Methods}

Taste and smell scores were calculated from the TSS and reported as mean $\pm \mathrm{SD}$. GCSI and $\mathrm{HB} / \mathrm{RG}$ were calculated from the PAGI-SYM and reported as mean \pm SD. Student's $t$ test was used to compare mean taste and smell scores from the 3 patient groups (gastroparesis, GERD, and gastroparesis/GERD) with mean scores of the healthy controls. Prevalence was calculated using mean $\pm 2 \mathrm{SD}$ of healthy controls as the upper limit of normal. Pearson's correlation was used to correlated both taste and smell scores with symptom scores (GCSI and $\mathrm{HB} / \mathrm{RG}$ ).

Table 1. Demographics for the 4 Study Groups

\begin{tabular}{|c|c|c|c|c|c|}
\hline & $\begin{array}{c}\text { Overall } \\
(\mathrm{N}=76)\end{array}$ & $\begin{array}{l}\text { Healthy Controls } \\
\qquad(\mathrm{n}=13)\end{array}$ & $\begin{array}{c}\text { Gastroparesis } \\
\quad(\mathrm{n}=30)\end{array}$ & $\begin{array}{l}\text { Gastroparesis/GERD } \\
\qquad(\mathrm{n}=23)\end{array}$ & $\begin{array}{l}\text { GERD } \\
(\mathrm{n}=10)\end{array}$ \\
\hline \multicolumn{6}{|l|}{ Gender } \\
\hline Male (n [\%)) & $8(11)$ & $2(15)$ & $2(7)$ & $0(0)$ & $4(40)$ \\
\hline Female (n [\%)) & $68(89)$ & $11(85)$ & $28(93)$ & $23(100)$ & $6(60)$ \\
\hline Age (mean $[\mathrm{SD}], \mathrm{yr}$ ) & $45(15)$ & $39(14)$ & $44(16)$ & $46(16)$ & $53(11)$ \\
\hline \multicolumn{6}{|l|}{ Race } \\
\hline White (n $[\%]$ ) & $59(78)$ & $7(54)$ & $26(86)$ & $20(87)$ & $6(60)$ \\
\hline African American (n [\%]) & $11(14)$ & $5(38)$ & $2(7)$ & $2(9)$ & $2(20)$ \\
\hline Other (n [\%]) & $6(8)$ & $1(8)$ & $2(7)$ & $1(4)$ & $2(20)$ \\
\hline $\mathrm{BMI}\left(\right.$ mean $\left.[\mathrm{SD}], \mathrm{kg} / \mathrm{m}^{2}\right)$ & $26(7)$ & $26(9)$ & $23(6)$ & $29(7)$ & $29(6)$ \\
\hline \multicolumn{6}{|c|}{ Etiology of Gastroparesis (n [\%]) } \\
\hline Idiopathic & - & - & $24(80)$ & $13(57)$ & - \\
\hline Diabetic & - & - & $5(17)$ & $8(35)$ & - \\
\hline Other & - & - & $1(3)$ & $2(8)$ & - \\
\hline
\end{tabular}

GERD, gastroesophageal reflux disease; BMI, body mass index. 


\section{Results}

\section{Study Population}

The study population included 76 subjects: healthy controls $(\mathrm{n}=13)$, gastroparesis $(\mathrm{n}=30)$, gastroparesis and GERD $(\mathrm{n}=$ $23)$, and GERD $(n=10)$. Sixty-eight subjects were female and 8 subjects were male. The mean age of the study population was 45 \pm 15 years. Fifty-nine $(78 \%)$ of subjects indicated they were white, $11(14 \%)$ of subjects indicated they were African American, and 6 $(8 \%)$ of subjects classified their race as "other." The average body mass index for the study population was $26 \pm 7 \mathrm{~kg} / \mathrm{m}^{2}$. Etiology of gastroparesis were evaluated. The diagnosis of idiopathic gastroparesis was present in 13 of 23 patients with gastroparesis and GERD and 24 of 30 patients with gastroparesis only. Breakdown of demographics for the 4 individual study groups can be seen in Table 1 .

\section{Taste and Smell Survey}

Average taste and smell scores from the TSS for all 4 study groups are listed in Table 2. Compared to healthy controls, taste and smell disturbances were significantly higher in patients with gastroparesis, GERD, and both gastroparesis and GERD. The mean taste score was significantly higher in the gastroparesis/GERD group than in the gastroparesis group alone $(5.13 \pm 3.06$ vs 3.13 $\pm 2.66, P=0.017$ ) (Table 2). The taste abnormality score significantly correlated with the smell abnormality score $(r=0.530, P=$ 0.001 ) (Table 3).

The mean $\pm 2 \mathrm{SD}$ of healthy controls as the upper limit of normal was used to calculate a prevalence of taste and smell abnormalities. The gastroparesis/GERD patients had the highest prevalence of both taste and smell abnormalities (70\% and 52\%, respectively) when compared to the gastroparesis patients (40\% and $40 \%)$, GERD patients (60\% and $40 \%)$, and healthy controls ( $8 \%$ and $8 \%)$. The prevalence of concurrent taste and smell abnormalities

Table 2. Taste, Smell, Gastroparesis Cardinal Symptom Index, and Heartburn and Regurgitation Scores in the 4 Study Groups

\begin{tabular}{|c|c|c|c|c|}
\hline & $\begin{array}{l}\text { Healthy controls } \\
\qquad(\mathrm{n}=13)\end{array}$ & $\begin{array}{l}\text { Gastroparesis } \\
\qquad(\mathrm{n}=30)\end{array}$ & $\begin{array}{c}\text { Gastroparesis/GERD } \\
(\mathrm{n}=23)\end{array}$ & $\begin{array}{l}\text { GERD } \\
(\mathrm{n}=10)\end{array}$ \\
\hline \multicolumn{5}{|l|}{ Taste scores (out of 10 points) } \\
\hline Mean $\pm \mathrm{SD}$ & $0.77 \pm 1.36$ & $3.13 \pm 2.66$ & $5.13 \pm 3.06$ & $3.80 \pm 3.33$ \\
\hline$P$-value vs healthy controls & - & $<0.001$ & $<0.001$ & 0.020 \\
\hline Prevalence $(\%>3.5)$ & $8 \%$ & $40 \%$ & $70 \%$ & $60 \%$ \\
\hline \multicolumn{5}{|l|}{ Smell scores (out of 6 points) } \\
\hline Mean $\pm \mathrm{SD}$ & $0.31 \pm 1.11$ & $2.10 \pm 1.94$ & $2.78 \pm 2.04$ & $2.30 \pm 2.63$ \\
\hline$P$-value vs healthy controls & - & $<0.001$ & $<0.001$ & 0.046 \\
\hline Prevalence $(\%>2.5)$ & $8 \%$ & $40 \%$ & $52 \%$ & $40 \%$ \\
\hline \multicolumn{5}{|l|}{ PAGI-SYM } \\
\hline GCSI (9 items): mean $\pm \mathrm{SD}$ & $0.36 \pm 0.53$ & $2.99 \pm 1.25$ & $3.06 \pm 1.07$ & $1.94 \pm 1.13$ \\
\hline $\mathrm{HB} / \mathrm{RG}(7$ items $):$ mean $\pm \mathrm{SD}$ & $0.10 \pm 0.19$ & $1.72 \pm 1.26$ & $2.40 \pm 1.28$ & $2.29 \pm 1.58$ \\
\hline \multicolumn{5}{|c|}{$\begin{array}{l}\text { GERD, gastroesophageal reflux disease; PAGI-SYM, Patient Assessment of Upper Gastrointestinal Symptom Severity Index; GCSI, Gastroparesis Cardinal } \\
\text { Symptom Index; HB/RG, Heartburn and Regurgitation Score. }\end{array}$} \\
\hline & \multicolumn{2}{|c|}{ Patients $(\mathrm{n}=63)$} & \multicolumn{2}{|c|}{ Total study $(\mathrm{n}=76)$} \\
\hline & $r$ & $P$ & $r$ & $P$ \\
\hline Taste vs GCSI & 0.401 & 0.001 & 0.536 & $<0.001$ \\
\hline Taste vs $\mathrm{HB} / \mathrm{RG}$ & 0.551 & $<0.001$ & 0.637 & $<0.001$ \\
\hline Smell vs GCSI & 0.367 & 0.003 & 0.495 & $<0.001$ \\
\hline Smell vs $\mathrm{HB} / \mathrm{RG}$ & 0.413 & 0.001 & 0.513 & $<0.001$ \\
\hline Taste vs smell & 0.457 & $<0.001$ & 0.530 & $<0.001$ \\
\hline
\end{tabular}

GCSI, Gastroparesis Cardinal Symptom Index; HB/RG, Heartburn and Regurgitation Score. 
Table 4. Breakdown of the Taste Complaints from the Taste and Smell Survey

\begin{tabular}{|c|c|c|c|c|}
\hline & $\begin{array}{l}\text { Healthy controls } \\
\qquad(\mathrm{n}=13)\end{array}$ & $\begin{array}{l}\text { Gastroparesis } \\
(\mathrm{n}=30)\end{array}$ & $\begin{array}{c}\text { Gastroparesis/GERD } \\
(\mathrm{n}=23)\end{array}$ & $\begin{array}{l}\text { GERD } \\
(\mathrm{n}=10)\end{array}$ \\
\hline \multicolumn{5}{|c|}{ Foods taste different than they used to } \\
\hline Yes & $3(23.1)$ & $10(33.3)$ & $12(52.2)$ & $4(40.0)$ \\
\hline No & $10(76.9)$ & $20(66.7)$ & $11(47.8)$ & $6(60.0)$ \\
\hline \multicolumn{5}{|c|}{ Comparison of sense of taste now to before diagnosis } \\
\hline \multicolumn{5}{|c|}{ I have noticed a change in salt } \\
\hline Yes & $1(7.7)$ & $12(40.0)$ & $11(47.8)$ & $4(40.0)$ \\
\hline No & $12(92.3)$ & $18(60.0)$ & $12(52.2)$ & $6(60.0)$ \\
\hline \multicolumn{5}{|l|}{ Salt tastes } \\
\hline Stronger & $0(0)$ & $5(16.7)$ & $7(30.4)$ & $1(10.0)$ \\
\hline Weaker & $1(7.7)$ & $7(23.3)$ & $3(13.0)$ & $1(10.0)$ \\
\hline Cannot taste & $0(0)$ & $0(0)$ & $1(4.4)$ & $2(20.0)$ \\
\hline \multicolumn{5}{|c|}{ I have noticed a change in sweet } \\
\hline Yes & $1(7.7)$ & $11(36.7)$ & $12(52.2)$ & $2(20.0)$ \\
\hline No & $12(92.3)$ & $19(63.3)$ & $11(47.8)$ & $8(80.0)$ \\
\hline \multicolumn{5}{|l|}{ Sweet tastes } \\
\hline Stronger & $1(7.7)$ & $9(30.0)$ & $6(26.1)$ & $1(10.0)$ \\
\hline Weaker & $0(0)$ & $2(6.7)$ & $5(21.7)$ & $1(10.0)$ \\
\hline Cannot taste & $0(0)$ & $0(0)$ & $1(4.4)$ & $0(0)$ \\
\hline \multicolumn{5}{|c|}{ I have noticed a change in sour } \\
\hline Yes & $0(0)$ & $7(23.3)$ & $16(69.6)$ & $5(50.0)$ \\
\hline No & $13(100)$ & $23(76.7)$ & $7(30.4)$ & $5(50.0)$ \\
\hline \multicolumn{5}{|l|}{ Sour tastes } \\
\hline Stronger & $0(0)$ & $6(20.0)$ & $9(39.1)$ & $3(30.0)$ \\
\hline Weaker & $0(0)$ & $1(3.3)$ & $7(30.4)$ & $2(20.0)$ \\
\hline Cannot taste & $0(0)$ & $0(0)$ & $0(0)$ & $0(0)$ \\
\hline \multicolumn{5}{|c|}{ I have noticed a change in bitter } \\
\hline Yes & $2(15.4)$ & $9(30.0)$ & $14(60.9)$ & $2(20.0)$ \\
\hline No & $11(84.6)$ & $21(70.0)$ & $9(39.1)$ & $8(80.0)$ \\
\hline \multicolumn{5}{|l|}{ Bitter tastes } \\
\hline Stronger & $0(0)$ & $7(23.3)$ & $7(30.4)$ & $1(10.0)$ \\
\hline Weaker & $2(15.4)$ & $2(6.7)$ & $6(26.1)$ & $1(10.0)$ \\
\hline Cannot taste & $0(0)$ & $0(0)$ & $1(4.4)$ & $0(0)$ \\
\hline \multicolumn{5}{|c|}{ Rate abnormal sense of taste } \\
\hline Insignificant & $13(100)$ & $18(60.0)$ & $6(26.1)$ & $4(40.0)$ \\
\hline Mild to moderate & $0(0)$ & $10(33.3)$ & $13(56.5)$ & $4(40.0)$ \\
\hline Severe to intolerable & $0(0)$ & $2(6.7)$ & $4(17.4)$ & $2(20.0)$ \\
\hline
\end{tabular}

GERD, gastroesophageal reflux disease.

Data are expressed as $n(\%)$.

was seen in $43 \%$ of patients with gastroparesis and GERD, $20 \%$ of patients with gastroparesis and $30 \%$ of patients with GERD.

Responses to questions analyzing specific patterns of taste and smell dysfunctions are shown in Tables 4 and 5. Patients were asked if foods (in general) tasted or smelled different than they used to. Nearly $52.2 \%$ of patients with both gastroparesis and GERD marked "yes" for changes in the taste of food, when compared to patients with gastroparesis $(33.3 \%)$ and patients with GERD (40.0\%) (Table 4). Interestingly, the smell of food was different in a greater number of patients with gastroparesis $(46.7 \%)$ than patients with GERD (40.0\%), and with both gastroparesis and GERD (39.1\%) (Table 5).

Changes in salt, sweet, sour, and bitter taste sensitivities were noted among the 3 patient groups. Among the patients in the 
Table 5. Breakdown of the Smell Complaints from the Taste and Smell Survey

\begin{tabular}{|c|c|c|c|c|}
\hline & $\begin{array}{l}\text { Healthy controls } \\
\qquad(\mathrm{n}=13)\end{array}$ & $\begin{array}{l}\text { Gastroparesis } \\
\quad(\mathrm{n}=30)\end{array}$ & $\begin{array}{c}\text { Gastroparesis/GERD } \\
(\mathrm{n}=23)\end{array}$ & $\begin{array}{l}\text { GERD } \\
(\mathrm{n}=10)\end{array}$ \\
\hline \multicolumn{5}{|c|}{ Foods smell different than they used to } \\
\hline Yes & $1(7.7)$ & $14(46.7)$ & $9(39.1)$ & $4(40.0)$ \\
\hline No & $12(92.3)$ & $16(53.3)$ & $14(60.9)$ & $6(60.0)$ \\
\hline \multicolumn{5}{|c|}{ Comparing smell now to before diagnosis } \\
\hline Stronger & $1(7.7)$ & $13(43.3)$ & $9(39.1)$ & $5(50.0)$ \\
\hline As strong/no change & $12(92.3)$ & $15(50.0)$ & $9(39.1)$ & $4(40.0)$ \\
\hline Weaker & $0(0.0)$ & $2(6.7)$ & $5(21.7)$ & $0(0.0)$ \\
\hline Cannot taste at all & $0(0.0)$ & $0(0.0)$ & $0(0.0)$ & $1(10.0)$ \\
\hline \multicolumn{5}{|c|}{ Rate abnormal sense of smell } \\
\hline Insignificant & $13(100.0)$ & $16(53.3)$ & $5(21.7)$ & $6(60.0)$ \\
\hline Mild to moderate & $0(0.0)$ & $9(30.0)$ & $11(47.8)$ & $1(10.0)$ \\
\hline Severe to intolerable & $0(0.0)$ & $5(16.7)$ & $7(30.4)$ & $3(30.0)$ \\
\hline
\end{tabular}

GERD, gastroesophageal reflux disease.

Data are expressed as n (\%).

gastroparesis/GERD group reporting that they noticed changes in their sensitivity to salt, sweet, sour, and bitter tastes, a majority indicated these 4 tastes to be stronger than weaker. Results differed among gastroparesis patients, where salt was noted to be weaker, and GERD patients, where no trends were seen for salt, sweet, and bitter tastes (Table 4). When asked to compare sense of smell now to before diagnosis of their respective upper GI disorders, $50.0 \%$ or more of the subjects in all 3 patient groups noted a change in smell function; many of these patients noted it to be stronger- $43.3 \%$ of patients with gastroparesis, $50.0 \%$ of patients with GERD, and $39.1 \%$ of patients with both gastroparesis and GERD (Table 5).

Patients were asked to rank the severity of their taste and smell abnormalities as insignificant, mild to moderate or severe, to intolerable, based on the impact on the quality of life. About $73.9 \%$ of patients with both gastroparesis and GERD indicated some degree of severity for their altered taste sensation: mild to moderate $(56.5 \%)$ and severe to intolerable (17.4\%). In comparison, $40.0 \%$ of patients with gastroparesis and $60.0 \%$ of patients with GERD ranked their taste abnormalities as either mild to moderate, or severe to intolerable (Table 4). When analyzing the effects of smell alterations on quality of life, $21.7 \%$ of patients with gastroparesis/GERD patients noted their altered sense of smell to be insignificant, when compared to gastroparesis (53.3\%) and GERD (60.0\%) patients (Table 5).

\section{Chemosensory Complaints and Upper Gastrointestinal Symptoms}

Pearson's correlation was used to analyze whether there was a relationship between symptom severity and chemosensory abnor- malities. Across the study groups ( $\mathrm{n}=76$ ), taste score was strongly correlated with $\mathrm{HB} / \mathrm{RG}(r=0.637, P<0.001)$ and with GCSI $(r=0.536, P<0.001)$; individuals experiencing a greater number of chemosensory abnormalities tend to have more severe upper GI symptoms. When assessing the relationship between smell score and the symptom scores, smell score also strongly correlated with $\mathrm{HB} / \mathrm{RG}(r=0.513, P<0.001)$ and GCSI $(r=0.495, P<$ $0.001)$.

\section{Discussion}

This study was designed to assess whether taste and smell abnormalities are present in patients with gastroparesis and/or GERD. The results of the study illustrate that taste and smell abnormalities are highly prevalent in patients with gastroparesis and/or GERD when compared to healthy controls. These taste and smell abnormalities positively correlated with upper GI symptoms of both gastroparesis and GERD. A breakdown of individual complaints showed that most patients with smell complaints noted this function to be stronger; reports of alterations in salt, sweet, bitter, and sour tastes were more diverse. While chemosensory changes are not standard symptoms evaluated in the care of gastroparesis and GERD patients, these findings indicate that taste and smell changes may contribute to the symptom burden in this subset of patients.

The clinical presentation of gastroparesis comprises of many upper GI symptoms; most patients report nausea and vomiting as the most prominent symptoms. ${ }^{3}$ We observed a striking correlation between gastroparesis symptom severity and increasing taste 
alterations. In patients with bulimia, it has been suggested that frequent vomiting of at least 3 times per week chronically exposes taste receptors, specifically on the palate, to hydrochloric acid of the stomach, and alters the ability of patients to taste salt, sweet, bitter, and sour solutions. ${ }^{10}$ Similar frequencies in vomiting are present in many patients with gastroparesis and could be contributing to the increasing taste abnormalities identified in patients with more severe symptoms.

We also determined that the GERD symptom profile positively correlated with taste scores. Symptoms of GERD are predominantly characterized by reflux of stomach acid and resulting heartburn. Retrograde movement of acid can pass through the entire upper GI tract into the oral cavity, resulting in erythema of the palatal mucosa, and uvula and epithelial atrophy. ${ }^{11}$ Like vomiting, acid reflux causes damage to the palate and has the potential to be the cause of taste abnormalities seen in our subjects with increasing severity in GERD symptoms.

Interestingly, we also determined that olfactory abnormalities positively correlated with both gastroparesis and GERD symptom severity. Upper GI symptoms are usually exacerbated with eating, causing many patients to avoid food, leading to the onset of nutritional deficiencies. ${ }^{4}$ Anorexia patients with a low body mass index (15 \pm 2 ), indicative of substantial decrease in eating, reportedly experience impairment in olfaction. ${ }^{12}$ Nutritional deficiencies, particularly proteins, decreases the ability of the GI epithelium to regenerate, which has been speculated to also affect the regeneration of olfactory epithelium, potentially serving as a cause of the smell dysfunction seen in malnourished anorexia patients. ${ }^{13}$ Similar symptoms of poor feeding and undernourishment secondary to GI distress could potentiate the smell impairment seen in our symptomatic gastroparesis and GERD patients.

At least one-third of the subjects in each of the patient groups indicated that foods smell and taste differently than prior to diagnosis. Hutten et $\mathrm{al}^{8}$ determined that patients with advanced cancer with alterations in taste and smell functions experienced decreases in nutrient intake, appetite, and food enjoyment. With a high prevalence of taste and smell abnormalities seen in our population, we expect that our patients' perception of foods is altered, especially with the complaints that both smells and tastes were distorted (stronger or weaker). These abnormalities could be an added factor, along with increasing symptom severity, that contributes to the food aversion and subsequent nutritional deficiencies commonly observed in patients with gastroparesis and with GERD.

Participants in our study are representative of the gastroparesis and GERD patients seen in the Temple's motility clinic. However, some limitations were identified. Sample bias was present as demonstrated by the variations in gender and race among the study groups. Gastroparesis predominantly affects females, which is why a majority of the study population was female. Since there were so few males in the study, we were unable to compare symptom profiles between the sexes. The 2 most common etiologies of gastroparesis are diabetic and idiopathic. ${ }^{2}$ Most patients in the study noted their etiology of gastroparesis to be idiopathic, and most noted their race to be white. Non-white patients more often tend to have gastroparesis of diabetic etiology, which usually presents later in life. ${ }^{14}$ The clinic sees many patients with idiopathic gastroparesis requiring regular follow-up visits, which could be why most of the patients randomly selected to participate in the study were white.

As can be seen in the questionnaire-based studies, recall bias may have led to either over-reporting or under-reporting of taste and smell abnormalities. Many of our patients have been diagnosed with gastroparesis and/or GERD for years, so comparison of taste and smell functions prior to diagnosis may have been difficult. Conducting formal chemosensory receptor analysis using taste and smell identification tests can help to determine whether taste and smell detection pathways are physically impaired, or whether there is a psychological factor contributing to the change in these sensory functions. We did not analyze the data collected on medications that each subject used due to inconsistencies in the subjects' recollection of their current medicines. Future studies would need to be conducted to look at whether particular medicines serve as effect modifiers between upper GI disorders and taste and/or smell changes.

In conclusion, our study shows that there are dramatic alterations in both taste and smell in patients with gastroparesis and/ or GERD. Taste and smell abnormalities were associated with increasing symptom severity, and may contribute to the food intolerances that many of these patients experience. While most patients reported worsening taste and smell function after diagnosis with gastroparesis and/or GERD, we did not assess a causal relationship between these 2 parameters. Further investigations can seek to determine whether taste and smell abnormalities are associated with a particular symptom profile or medications used to treat GI symptoms, and whether changes in these 2 functions impact the quality of life among patients with GI disorders.

\section{Financial support: None.}

\section{Conflicts of interest: None.}

Author contributions: Alisha Kabadi: study concept and 
design, data entry, analysis and interpretation of data, statistical analysis, and drafting of the manuscript; Mohammed Saadi: study concept and design, interpretation of data, and reviewing manuscript; Ron Schey: study concept and design, interpretation of data, and reviewing manuscript; and Henry P Parkman: study concept and design, analysis and interpretation of data, critical revision of the manuscript for important intellectual content, and study supervision.

\section{References}

1. Enweluzo C, Aziz F. Gastroparesis: a review of current and emerging treatment options. Clin Exp Gastroenterol 2013;6:161-165.

2. Oh JH, Pasricha PJ. Recent advances in the pathophysiology and treatment of gastroparesis. J Neurogastroenterol Motil 2013;19:18-24.

3. Tavokoli A, Sayed BA, Talley NJ, Moshiree B. Acid and non-acid reflux in patients refractory to proton pump inhibitory therapy: is gastroparesis a factor? World J Gastroenterol 2013;19:6193-6198.

4. Parkman HP, Yates KP, Hasler WL, et al. Dietary intake and nutritional deficiencies in patients with diabetic or idiopathic gastroparesis. Gastroenterology 2011;141:486-498, e1-e7.

5. Bromley SM. Smell and taste disorders: a primary care approach. Am Fam Physician 2000;61:427-436, 438.

6. Alvarez-Camacho M, Gonella S, Gosh S, et al. The impact of taste and smell alterations on quality of life in head and neck cancer patients. Qual Life Res 2016;25:1495-1504.

7. Heald AE, Pieper CF, Schiffman SS. Taste and smell complaints in HIV-infected patients. AIDS 1998;12:1667-1674.

8. Hutten JL, Baracos VE, Wismer WV. Chemosensory dysfunction is a primary factor in the evolution of declining nutritional status and quality of life in patients with advanced cancer. J Pain Symptom Manage 2007;33:156-165.

9. McGreevy J, Orrevall Y, Belqaid K, Wismer W, Tishelman C, Bernhardson BM. Characteristics of taste and smell alterations reported by patients after starting treatment for lung cancer. Support Care Cancer 2014;22:2635-2644.

10. Sipiora ML, Murtaugh MA, Gregoire MB, Duffy VB. Bitter taste perception and severe vomiting in pregnancy. Physiol Behav 2000;69:259267.

11. Rajitkar S, Smales RJ, Kaidonis JA. Oral manifestations of gastroesophageal reflux disease. J Gastroenterol Hepatol 2012;27:21-27.

12. Aschenbrenner K, Scholze N, Joraschky P, Hummel T. Gustatory and olfactory sensitivity in patients with anorexia and bulimia in the course of treatment. J Psychiatr Res 2008;43:129-137.

13. Fedoroff IC, Stoner SA, Andersen AE, Doty RL, Rolls BJ. Olfactory dysfunction in anorexia and bulimia nervosa. Int J Eat Disord 1995; 18:71-77.

14. Friedenberg FK, Kowalczyk M, Parkman HP. The influence of race on symptom severity and quality of life in gastroparesis. J Clin Gastroenterol 2013:47:757-761 